\title{
CARDOSO VIEIRA, UM HOMEM NEGRO NA COMPOSIÇÃO DAS ELITES DA PARAIBA OITOCENTISTA: Biografia, Memória e História1
}

\section{CARDOSO VIEIRA, A BLACK MAN IN THE COMPOSITION OF THE ELITES OF PARAIBA 18TH: Biography, memory and history}

RESUMO: Entre as muitas renovações na produção do conhecimento histórico com o movimento dos Annales, iniciadas nos anos finais da década de 1920, destacamos a revalorização do gênero biográfico para recuperar trajetórias de indivíduos (in)comuns e extraordinários, com o intuito de observá-los não como heróis, mas como sujeitos sociais que representaram a história de uma determinada época. Nesse sentido, com base em dados biográficos (CASTRO, 1955, MARTINS, 1979), procurei analisar a trajetória de um homem negro livre - Manoel Pedro Cardoso Vieira - que se destacou na cena política, intelectual e econômica da Paraiba escravista no Oitocentos. Ademais, investiguei as narrativas memorialísticas e históricas construídas sobre ele (POLLAK, 1989, NORA, 1993), que pode ser considerada a escrita do outro, com o propósito de compreender as múltiplas facetas desse sujeito, que teve solidificada uma determinada imagem um dos "vultos da história da Paraíba" - durante um longo do tempo, entre 1892 e 1979, e que mais recentemente, outras imagens têm sido recuperadas, no espaço acadêmico, como um homem negro integrante das elites imperiais e também um sujeito multifacetado e controverso que teve uma trajetória de vida marcante na complexa sociedade escravista no final do Império brasileiro.

Palavras-chave: Biografia histórica, Cardoso Vieira, Paraíba escravista.

Abstract: Among the many renovations in the production of historical knowledge with the Annales movement that began in the final years of the 1920s, highlight the upgrading of the biographical genre to recover trajectories of individuals (in) ordinary and extraordinary, in order to observe them not as heroes, but as social individuals who represented the story of a particular time. Accordingly, based on biographical data (CASTRO, 1955, Martins, 1979), tried to analyze the trajectory of a free black man - Manoel Cardoso Pedro Vieira - who stood out in the political, intellectual and economic slavery of Paraiba in the nineteenth century. Furthermore, I investigated the historical narratives memorialistics and built on it (Pollak, 1989, NORA, 1993), which can be considered the writing of another with the purpose of understanding the multiple facets of this subject, which had solidified a certain image - one of "figures in the history of Paraiba" - for a long time, between 1892 and 1979, and more recently, other images have been recovered in the academic space, as a black man and a member of the imperial elites also a multifaceted and controversial subject that had a remarkable life trajectory in the complex slave society at the end of the Brazilian Empire.

Key-words: Historical biography, Cardoso Vieira, slavery in Paraíba

1 As reflexões presentes neste artigo foram expostas na Mesa Redonda Escravidão, Resistência e Movimento Negro, no IV Encontro Nacional de História e I Seminário Nacional LAHAFRO/NEAB, em outubro de 2012, na Universidade Federal de Alagoas.

2 Solange Pereira da Rocha é doutora em História pela UFPE. Atualmente é professora do Departamento de História e do Programa de Pós-graduação em História da UFPB. 


\section{INTRODUÇÃO}

Em 1848, no interior do Brasil oitocentista, na freguesia litorânea de Jacoca (atual município do Conde/Paraíba), nasceu Manoel Pedro Cardoso Vieira. ${ }^{3}$ Para alguns, esse nome talvez se refira a algum logradouro das três principais cidades da Paraíba - João Pessoa, Campina Grande e Santa Rita - mas também, para muitos, pode não significar nada. Quem era, então, Manoel Pedro Cardoso Vieira? Nos anos finais de 1870, ele era conhecido como o Deputado Geral Manoel Pedro, visto que assumiu uma vaga na Assembleia Geral, no Rio de Janeiro. Essa participação no Legislativo nos indica que ele foi uma figura importante na cena política da Parahyba Imperial. Ademais, foi advogado, fundador de jornal, orador, poeta, jornalista de vários periódicos e professor do Lyceu Provincial da Parahyba do Norte. Adorava uma polêmica e, quase sempre, esteve envolvido em disputas e conflitos políticos. Depois de morto - aos 32 anos, em 1880 - se tornou um "imortal", patrono da Cadeira 10, da Academia Paraibana de Letras/APL, criada em 1941. Como podemos observar, a vida dele, apesar de breve, foi intensa, com uma interessante trajetória. Contudo, destaco que, além de sua ascensão política partidária meteórica, ele era um homem negro, que vivia num contexto em que predominavam as teorias sobre degeneração e a inferioridade da população miscigenada [e negra] (ANDREWS, 2007) e predominava o estigma da escravidão, que, se não impedia a inserção social de pessoas negras, sem dúvida, dificultava a movimentação nos círculos das elites oitocentistas.

Contudo, a origem racial de Cardoso Vieira não o impediu de ser reconhecido, quando vivo e depois de morto, pela elite intelectual e política da Parahyba. Nos escritos biográficos sobre esse personagem, em geral, ele foi identificado como um "mulato" (ou, como alguns preferiam, "mestiço"), que atuou ativamente social e politicamente, e que, passados 132 anos da sua precoce morte, continua presente na memória da Paraíba.

3 A sistematização da trajetória de vida de Manoel Pedro Cardoso Vieira (1848-80) é um dos resultados do projeto de pesquisa Gente Negra na Paraiba Oitocentista: redes sociais e arranjos familiares, desenvolvido entre 2011 e 2012, contou com apoio do Conselho Nacional de Desenvolvimento Científico e Tecnológico/CNPq. Em certa medida resulta, também, de frutiferos debates entre dois Grupos de Pesquisa da UFPB, o Sociedade e Cultura no Nordeste Oitocentista, do qual faço parte, e o História da Educação no Nordeste Oitocentista, que tem realizado discussões de temas em comuns, como a sociedade e a cultura política no século XIX. Aproveito, ainda, para agradecer Antônio Novaes, Cristiano Ferronato e Terlúcia Silva pelos comentários pertinentes e pelas sugestões dadas com o intuito de melhorar a compreensão do texto. Agradeço, por fim, a colaboração de Josilene Pacheco, que realizou pesquisa nos acervos paraibanos, para ampliar as informações históricas sobre Cardoso Vieira. 
Com os dados históricos obtidos na pesquisa pude recuperar a trajetória do personagem aludido e também, como é comum na História, procurei recompor o universo social de uma época, com suas contradições e complexidades. Nesse sentido, ao analisar a vida de Cardoso Vieira (1848-80), temos elementos para compreender a inserção social de pessoas negras livres na sociedade oitocentista, indo além da ideia naturalizada que se tem delas, vinculadas à escravidão, sendo escravizadas ou libertas. Ademais, possibilita conhecermos fragmentos históricos da sociedade oitocentista e a cultura histórica, ou seja, a narrativa do passado produzida por homens de letras, referente às imagens construídas sobre o multifacetado Cardoso Vieira, presente até os dias de hoje na Paraíba. Nesse sentido, realizei o "enquadramento da memória" de Cardoso Vieira, com vistas a historicizar as imagens construídas sobre ele, a partir de análises de escritos de intelectuais do IHGP e da APL, que, em geral, investiram na consagração de sua memória, evidenciando suas atuações como intelectual e como parlamentar, cuja memória deveria ser lembrada, celebrada e cultuada pela sociedade, especialmente, como exemplo para as futuras gerações, afinal, na visão de Martins (1979, p. 15), que iniciou a biografia dele com considerações de Manoel Tavares Cavalcanti (1880-1950), que destacou a breve vida de Cardoso Vieira e sua marcante atuação. Segundo as palavras de Cavalcanti, apesar dele ter vivido pouco e falecido "no princípio de uma carreira que tanto prometia a Paraíba", seu "nome [é] inapagável e as coroas das primeiras vitórias gloriosas" (apud MARTINS, 1979, p. 15).

O contexto da atuação política mais sistemática de Cardoso Vieira, os anos de 1870, foi marcado por importantes mudanças socioeconômicas ocorridas no Brasil escravista. No que se refere às relações de trabalho, predominava a mão de obra de mulheres e de homens escravizados, todavia, o regime escravista estava em plena crise e, portanto, em processo de mudanças. Porém as transformações no mundo de trabalho se refletiram com a aprovação da Lei Rio Branco (mais conhecida como do Ventre Livre ou Lei 2040), que determinava: a libertação do ventre escravo; a realização de matrícula nacional dos escravizados; a criação de um fundo de emancipação dos cativos; o reconhecimento do direito de escravizados à autocompra e de litigarem na justiça em defesa de sua liberdade. Além disso, a entrada em vigor da mencionada lei abria possibilidades para que os escravizados recorressem à Justiça para conquistar a liberdade e reforçava o "clima de apreensão" por parte dos escravizadores, que temiam o fim do regime escravista. Nessa época, as elites brasileiras já havia estabelecido um consenso acerca da "emancipação gradual" da escravidão no Brasil. Essa visão estava em consonância com a ideologia liberal - base da política imperial - que sacralizava o direito à propriedade privada (CONRAD, 1978; PRADO, 2001). 
Nos anos finais da década de 1870, no plano político, o Partido Liberal retornou ao poder central, depois de um ostracismo político de dez anos. A região de origem de Cardoso Vieira, o Nordeste (então designada como Norte ${ }^{4}$ ), vivia um momento difícil, uma vez que a agroindústria açucareira estava em crise. A lavoura algodoeira amenizava esse quadro, contudo, no Sudeste, o café figurava como principal produto de exportação do país, porquanto recebia expressivo apoio governamental para modernizar sua infraestrutura. O Norte, por sua vez, ainda teve que enfrentar a "grande seca" - nos anos de 1877, 1878 e 1879 - que solapou não apenas suas lavouras, mas também a dita "propriedade" - o cativo -, cujo número diminuía, a cada ano, em razão da morte ou da transferência para o Sudeste, pela via do tráfico interprovincial.

Vejamos a trajetória do paraibano Cardoso Vieira na referida época. Ele se elegeu nessa conjuntura, caracterizada no plano nacional pela ascensão dos liberais no comando do país e, no plano regional, como dito, um período marcado por dificuldades econômicas e perda de poder político das elites do Norte, que teve que enfrentar questões da política econômica como as analisadas por Mello (1999), a saber: "tráfico interprovincial de escrav[izad]os; a imigração estrangeira; o financiamento da grande lavoura; a modernização da agroindústria açucareira; o desenvolvimento do sistema de transportes e a divisão de rendas entre o governo central e as províncias". Enfim, esse era o cenário que o jovem deputado Cardoso Vieira encontrou e sobre o qual procurou se posicionar nos debates e embates realizados nos periódicos e na Assembleia Geral. Vale salientar que, na legislatura do qual ele fez parte, entre 1878 e 1881, estava presente seu colega da Faculdade de Direito de Recife, Joaquim Nabuco, que surgia como uma das principais lideranças do movimento abolicionista no parlamento.

Assim, neste estudo, procurei apresentar o personagem histórico Cardoso Vieira, identificando suas origens e trajetória política na segunda metade do Oitocentos, buscando compreender as múltiplas facetas desse sujeito, que teve solidificada determinada imagem - um dos "vultos da história da Paraíba" - ao longo do tempo e, investiguei também as narrativas memorialísticas e históricas construídas sobre ele, realizando um enquadramento de sua memória, para evidenciar as imagens construídas sobre ele no contexto dos séculos XIX e do XX.

4 Conforme nos informa Mello (1999, p. 15), para "os homens públicos do Império [...], a geografia regional do Brasil era bem simples: havia as províncias [...] do norte, do Amazonas à Bahia, e as províncias [...] do sul, do Espírito Santo ao Rio Grande [Sul]". "Nada de Nordeste, Sudeste ou Centro-oeste." Grifos meus. No presente texto, empregarei tanto os termos de época - Norte ou Centro-sul - quanto dos atuais para me referir às províncias imperiais - Nordeste ou Sudeste. 


\section{CARDOSO VIEIRA: HISTÓRIA E MEMÓRIA}

Como já mencionado, o "mulato" Cardoso Vieira era um homem livre, filho de pais proprietários de terras no litoral da Paraíba, e de pessoas escravizadas - cerca de uma dezena de cativos. Ele estudou no Lyceu Provincial da Parahyba do Norte ${ }^{5}$ e na Faculdade de Direito de Recife. Como era comum entre os homens das elites do século XIX, exerceu várias funções profissionais e políticas, assim, tornou-se professor de Retórica no Lyceu Paraibano, foi jornalista de alguns periódicos políticos e, aos 30 anos, elegeu-se deputado geral pela Paraíba, como representante do Partido Liberal, na $17^{\text {a }}$ Legislatura, no período de 1878 a 1881, e fez parte do grupo de parlamentares que defendiam o fim imediato da Abolição.

No início de 1880, algo de inesperado ocorreu: o seu falecimento, quando vivia na capital do Império, no exercício do cargo de deputado geral. Morreu vítima da denominada "febre perniciosa". Pela sua trajetória política, esse desaparecimento físico pode ter sido considerado por setores da elite como uma promessa que não se cumpriu. Afinal, nas disputas para escolha de candidatos do Partido Liberal da Paraíba, para a legislatura de 1878-81, seu nome foi escolhido em detrimento de outros, como 0 do líder do seu partido, João Leite Ferreira, considerado a "maior expressão dos quadros partidários da província" [da Paraíba, a partir dos anos finais da década de 1860] (MARIZ, 1980, p. 166-169), que era "fascinado pelo talento de Manoel Pedro Cardoso Vieira". De fato, ele compôs a chapa de candidatos junto com mais quatro liberais - Manoel Vicente Magalhães, Aragão e Melo, João Florentino e Manoel Carlos (MARIZ, 1980, p. 166-169).

Começava, então, o personagem central desse artigo, sua experiência como parlamentar no legislativo federal, exercendo o cargo de deputado geral, e, destaco, que a ao longo de sua vida sua atuação política e intelectual sempre foi lembrada como um homem de talento, inteligente, elegante e também agressivo e desrespeitoso (MARTINS, 1979). O seu biógrafo, Martins (1979, p. 38), destaca que essas duas últimas qualidades the criaram a "auréola imperecível entre os que chegaram a ouvilo e também antipatias e inimizades profundas". Grifos meus.

5 Ferronato (2012), em sua tese de doutoramento sobre o Lyceu Provincial, afirma que, na documentação pesquisada sobre a instituição, não foi possível identificar as datas de entrada e de saída de Cardoso Vieira como aluno, apenas como professor.

6 Sobre o tema, consultar Marcílio, Maria Luiza. Mortalidade e morbidade da cidade do Rio de Janeiro Imperial. R. História, São Paulo, n-127-128, p. 53-68, ago-dez/92 a jan-jul/93. 
Como mencionado, a memória de vida de Cardoso Vieira não ficou silenciada. Pelo contrário, ela sempre foi utilizada pelos intelectuais da Paraíba, em geral, associados a instituições culturais, como o IHGP, fundado em 1905, e a APL, criada em 1941, que atuaram (atuam) na construção da identidade paraibana, e Cardoso Vieira, como veremos, tem sido destacado como um homem que muito orgulhou a Paraíba, um dos "vultos" da sua história.

Como se sabe, os institutos históricos, criados no Brasil, a partir de 1838, tinham como objetivos elaborar uma história nacional ou local, solidificar mitos fundadores e heroicizar indivíduos que participaram de "grandes feitos históricos" considerados relevantes por aqueles que compunham essas instituições, em geral, historiadores autodidatas, que exerciam funções diversas, como jornalistas, políticos, advogados e médicos. Na Paraíba, não foi diferente, no início da República, em 1905, criou-se o IHGP. Os estudos elaborados por homens desse instituto visavam construir um discurso fundador da identidade local, denominada de paraibanidade, caracterizada pela bravura e pelo caráter republicano e pacífico do povo da Paraíba (DIAS, 1996, p. 63).

Nesse sentido, são pertinentes as considerações de Castro (1955, s/p) que, na década de 1950, esforçou-se por "recompor o perfil biográfico [...] dos paraibanos ilustres" integrantes da APL, então com 30 patronos, com vistas a "conseguir apanhar-lhes as fotografias". Para Castro (1955), era uma forma de se buscar o "passado [de] uns tantos vultos do [...] patrimônio literário e histórico" da Paraíba, com o intento de mostrar que eles tinham "valores morais", que valorizavam o paraibano. Considerava, ainda, que havia nesses homens, sobretudo os envolvidos com as letras e com a política, "certa condição psicológica que o coloca[va] numa situação distinta no seio do Nordeste brasileiro" (CASTRO, 1955, s/p).

Entre esses "homens de pensamento", estava Cardoso Vieira, qualificado como "talentoso mestiço, que representou a Paraíba na Assembléia Geral do Império". Assim, podemos observar que Castro, a despeito da origem racial, procurou destacar que ele era um indivíduo com habilidade ou capacidade extraordinária, pois estava junto de um grupo de "imortais", sobre os quais se desejavam fixar uma imagem positiva. Nesse sentido, o literato José Lins do Rego, responsável pelo prefácio do livro mencionado, reafirma essa visão, ao enfatizar que a galeria dos patronos da APL iria apresentar "os homens verdadeiramente representativos que ficaram com sementes que não apodrecem" (CASTRO, 1955, s/p). Assim, o escritor José Lins finalizou afirmando: "A galeria que o Prof. Oscar de Castro reuniu merece ser divulgada, para que se restabeleçam valores que não devem permanecer no olvido" (CASTRO, 1955, s/p). No Quadro 1, destacamos a fotografia de Cardoso Vieira, publicada por 
Castro, que segundo suas palavras foram "tortuosos os caminhos" para comprovar a autenticidade da imagem do "talentoso paraibano".

De fato, a sua trajetória não ficou no "olvido", em razão da celebração de sua memória pelos letrados da Paraíba, que esteve, frequentemente, a celebrar a sua memória, rememorando acontecimentos vividos por ele, com vistas a solidificar e fixar uma imagem positiva dele e da própria Paraíba. Com o objetivo de visualizar essas informações memorialísticas sobre ele, procurei selecionar e analisar os escritos produzidos acerca de sua trajetória, publicadas desde o final do século XIX até a segunda metade do século XX, com base em Martins (1979) e Mello (1988), procurando ir além das indicações dos dois autores mencionados, acrescentando documentos, e examinando estudos bibliográficos disponíveis nas bibliotecas paraibanas. Mas, em geral, esse estudo se baseou, sobretudo, nas informações históricas indiretas oriundas dos escritos de homens do Instituto Histórico e Geográfico Paraibano/IHGP e da Academia Paraibana de Letras/APL. Em investigação futura, pretendo, ampliar estudos sobre Cardoso Vieira tendo como perspectiva a categoria Cultura Histórica ${ }^{7}$ que envolveu a construção da sua memória.

7 Cultura Histórica entendida na perspectiva de Chaves (2007, p. 95), com um "pensar historicamente que estão aquém e além do campo da historiografia e do cânone historiográfico. Trata-se da intersecção entre a história científica, habilitada no mundo dos profissionais como historiografia, dado que se trata de um saber profissionalmente adquirido, e a história sem historiadores, feita, apropriada e difundida por uma plêiade de intelectuais, ativistas, editores, cineastas, documentaristas, produtores culturais, memorialistas e artistas que disponibilizam um saber histórico difuso através de suportes impressos, audiovisuais e orais", entre os quais estão os intelectuais vinculados ao IHGP e a APL, que produziram (e produzem) representações do passado. 


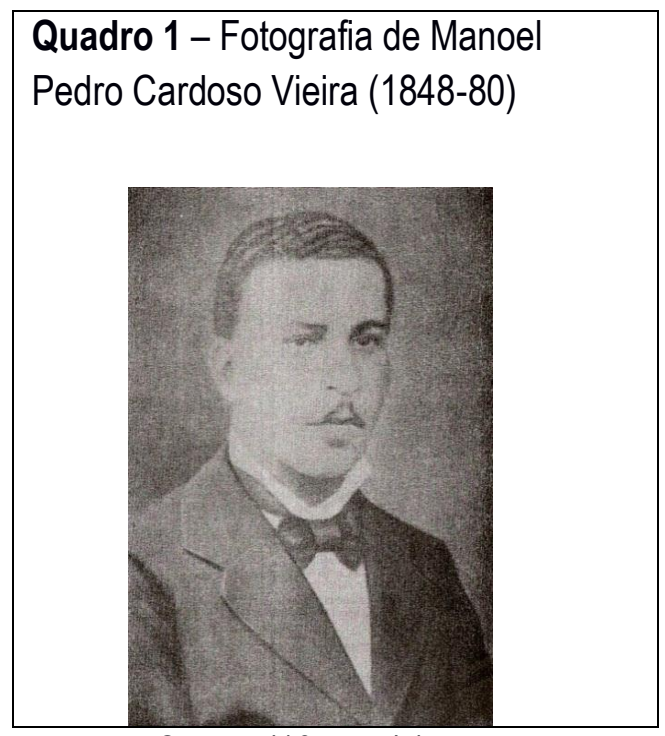

Fonte: Castro (1955, s/p)

Assim, vamos nos debruçar sobre os fragmentos de sua memória que foram preservados e relembrados pelas elites da Paraíba, em diferentes momentos históricos, tanto para indicar como um integrante da intelectualidade paraibana, quanto para nomear associações culturais e para designar logradouros públicos.

Vejamos aos escritos memorialísticos sobre Cardoso Vieira. Passados doze anos de sua morte, em 1892, temos uma primeira informação sobre o letrado "mestiço". Um grupo de intelectuais paraibanos se juntou, com vistas a criar um "clube" para promover eventos literários na Paraíba. Assim, em 03 de abril de 1892, criaram o Clube Cardoso Vieira, cujas instalações se localizavam na região central de João Pessoa, na Rua Maciel Pinheiro, nº 50 (MARTINS, 1978, e GUIMARÃES, 2001).

São poucas as informações a respeito desse clube. Guimarães (2001, p. 14) salientou que 0 objetivo "maior era a instrução", e sua formação inicial contava com nove homens: José Rodrigues, José Holmes, Idalino Júnior, Francisco Vidal, Antônio Lyra, Elyseu Cezar, Diomedes Cantalice, Antônio Espínola e Manoel Antônio. Além desse "clube", outros foram criados na década de 1890, como o Centro Literário Paraibano e o Clube Literário Benjamin Constant (1899), entretanto, nenhum conseguiu se consolidar no século XIX como espaço para o debate literário na Paraíba (GUIMARÃES, 2001, p. 14).

Iniciado o século XX, como dito anteriormente, no ano de 1905, nasceu o Instituto Histórico e Geográfico Paraibano (IHGP), que se mantém até os dias atuais em atividade (com 107 anos, completados em 07/09/2012). Todavia, a motivação de se criar um espaço para discussões literárias 
não foi abandonada. Em 1917, muitos dos homens envolvidos na formação do IHGP estavam fundaram a Associação de Homens de Letras, com o intuito de divulgar estudos literários, mas sua sobrevivência também foi breve - de apenas três anos. Acerca dessa associação, temos informações dos patronos escolhidos por seus idealizadores. Nesse sentido, Álvaro de Carvalho, que foi vicepresidente do estado da Paraíba, 1928-1930 e fundador do IHGP e da APL, havia escolhido como patrono Cardoso Vieira; Manoel Tavares Cavalcanti, por sua vez, indicou o Visconde de Cavalcanti (Diogo Velho Cavalcanti de Albuquerque); já Rodrigues de Carvalho e Irineu Pinto preferiram, respectivamente, Aristides Lobo e Maximiano Machado (GUIMARÃES, 2001, p. 17). Percebemos, assim, no início do século $\mathrm{XX}$, a permanência do paraibano negro entre os memoráveis da intelectualidade paraibana.

Ao ler o livro de Rodriguez (1962, p. 33), percebi que, desde 1918, um dos logradouros centrais de João Pessoa homenageava Cardoso Vieira. A respeito da Rua Cardoso Vieira, Rodriguez (1962, p. 36) mencionou que, anteriormente, era conhecida como "antiga [Rua] Montenegro, também conhecida como Rua dos Portões. [Mudou para notabilizar] Manuel Pedro Cardoso Vieira, formado em Direito, advogado, jornalista, grande orador, natural deste Estado." Identificamos, assim, nos estudos de Rodriguez, cuja primeira edição data de 1962, que, na primeira metade do século XX, as autoridades paraibanas continuavam a distinguir o personagem em estudo.

\section{Quadro 2 - Mapa atual de João Pessoa, com identificação da Rua Cardoso Vieira}

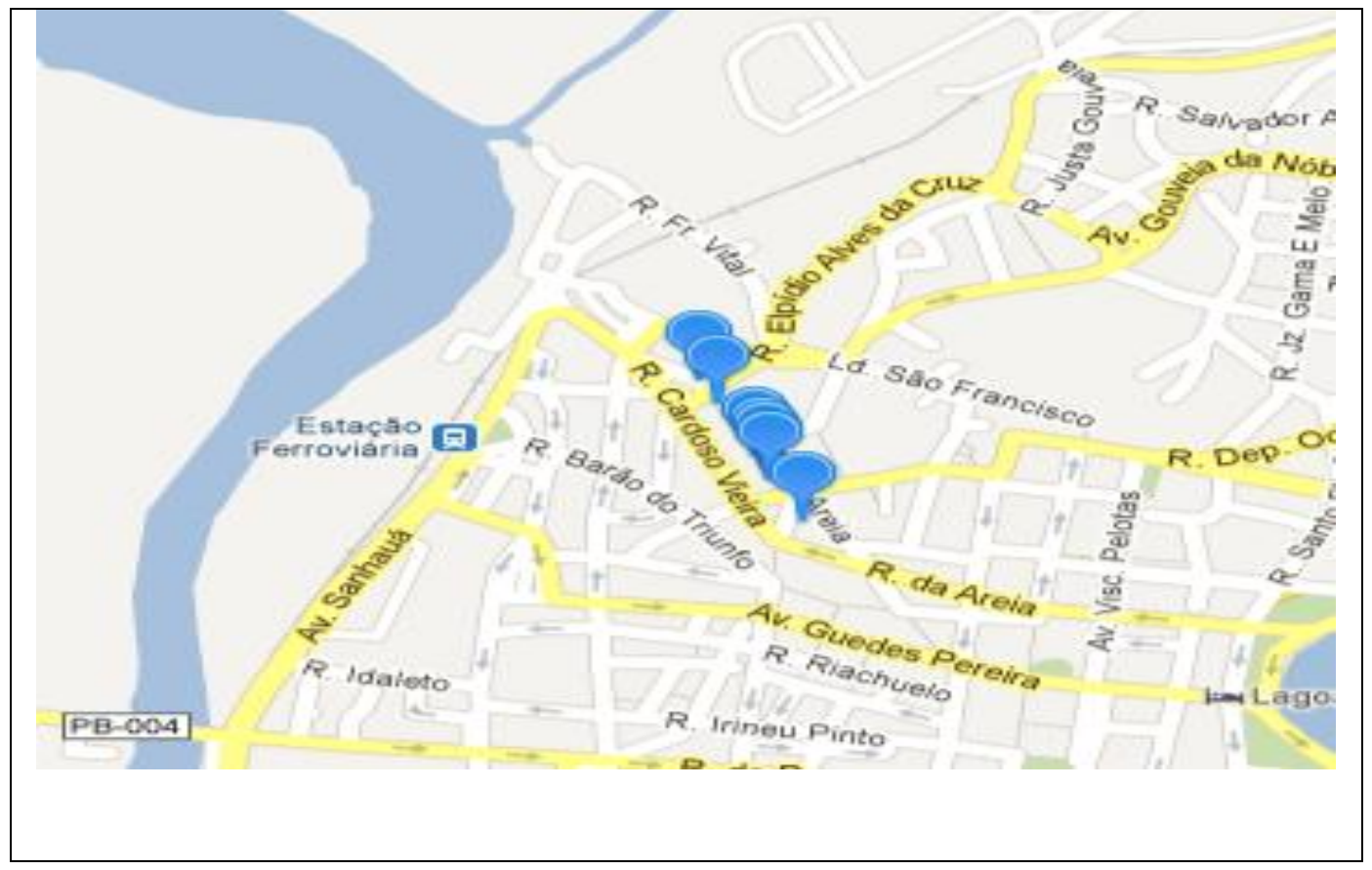


FONTE: Mapa disponível no portal da http://imigra.com.br/ruas/pb/joao-pessoa/rua-cardoso-vieira.

Acesso em: 20 jun. 2012.

$\mathrm{Na}$ atualidade, passados 132 anos da morte de Cardoso Vieira, essa rua mantém o seu nome (ver imagem no Quadro 2), possivelmente, o primeiro negro que era advogado, jornalista e deputado na Paraíba e também era homenageado pelas autoridades públicas nomeado logradouros públicos, um lugar da memória para evocação do passado e presentificação de uma experiência humana, no caso Cardoso Vieira, para ser relembrado e reconhecido para ser transmita aos pósteros (POLLAK, 1989, NORA, 1993).

Na década seguinte, em 1923, com a publicação do livro de José Américo de Almeida, A Paraíba e seus problemas, o autor destaca a atuação parlamentar do deputado negro, por ocasião das discussões sobre defesa de recursos para atender aos "flagelados" da seca. Nas palavras de Almeida, "e o débil protesto de fome repercutiu na eloquência de Cardoso Vieira, que estrondou, na Câmara dos deputados, em reptos de piedade e de revolta" (ALMEIDA, 1994, p.198).

Também na década de 1920, Celso Mariz, intelectual vinculado ao IHGP, em 1922, publicou 0 livro Apanhados históricos da Paraíba, no qual evidenciou os arranjos políticos que resultaram na indicação e eleição de Cardoso Vieira para deputado geral. Segundo o mencionado autor, a disputa pela indicação foi acirrada, porque vários políticos do Partido Liberal ambicionavam a vaga de deputado geral. Contudo, como dito anteriormente, a "chefia" do Partido, nas mãos de João Leite Ferreira, abriu mão de sua indicação em favor do "nome de Cardoso Vieira" (MARIZ, 1980, p. 166-169), que na época era redator do "órgão do Partido" liberal, ou seja, o jornal O Despertador, cuja tipografia funcionava em sua casa, no centro da cidade da Parahyba, a capital da província (MARTINS, 1979, p. 41).

Mariz, estudioso do IHGP, que publicou inúmeros estudos sobre a política paraibana, ao analisar o desempenho dos políticos paraibanos, não deixou de mencionar Cardoso Vieira qualificado como um "meteoro genial do mestiço Cardoso Vieira, falecido em 1880. A Paraíba continuava a honrar o Parlamento" (MARIZ, 1980, p. 169). Como exposto, Mariz recupera a origem racial e o coloca não só como um político "genial", mas também como um homem que representava a Paraíba no cenário nacional e a sua rápida ascensão política, que mantinha a "honra" dos parlamentares da Paraíba. 
Nas primeiras décadas do século XX, novas tentativas de se fundar associações de estudos literários foram executadas pelos intelectuais paraibanos. De tal maneira, que em setembro de 1941, após instigações do IHGP e da Federação de Academia de Letras, fundou-se a APL. Essa entidade cultural iniciou suas atividades culturais com dez associados, com o propósito de "perpetuar as tradições literárias da Paraíba" (MARTINS, 1984, p. 215). Assim, a Paraíba foi o último estado brasileiro a fundar sua Academia de Letras.

No mês seguinte à criação da APL - outubro de 1941 - foi constituída a primeira diretoria, cujo presidente foi Coriolano de Medeiros (biênio 1941-43). Uma das primeiras ações da diretoria foi a escolha dos trinta patronos da mencionada Academia. Novamente, percebemos uma homenagem a Cardoso Vieira, que passou a ser o patrono da Cadeira 10.8 Mais de seis décadas depois do seu falecimento, ele continuava a ser relembrado e criavam-se maneiras de se cristalizar sua imagem como um integrante da intelectualidade paraibana.

Essa memória continuou a repercutir nos anos e nas décadas seguintes. Talvez o fato de ter sido escolhido como patrono de uma das cadeiras da APL levou à necessidade de se organizarem mais informações sobre sua vida. Por esse motivo, talvez, não tenha sido coincidência que, em 1948, ano do seu centenário de nascimento, Álvaro de Carvalho tenha escrito um artigo intitulado Notas sobre Cardoso Vieira, publicado na Revista da APL, que reconstitui importantes momentos de sua vida e mostra-o como um homem multifacetado, com intensa atuação política, que antes de sua chegada ao Parlamento, se caracterizava pelas polêmicas travadas nos periódicos, uma das principais "arena política" do período oitocentista, nos quais se discutiam os assuntos de interesse de grupos políticos e, em geral, da sociedade brasileira.

Ressalto, portanto, que, se compararmos o Cardoso Vieira político e jornalista com outros intelectuais e políticos do Oitocentos, veremos que ele não é uma exceção. Como outros homens letrados de seu tempo, se inseriu publicamente em várias frentes políticas. Assim, ele foi fundador de um jornal (Bossuet da Jacoca), escreveu e dirigiu vários periódicos (O Despertador, União Liberal, 0 Publicador), se tornou professor de escola secundária (Lyceu Paraibano) e exerceu a advocacia (atuou no julgamento de Carlos Holmes, segundo Martins (1979, p.38-39). Não deixou também de enfrentar polêmicas políticas ao escrever nos periódicos imperiais. Como ele, outros políticos e profissionais do período Imperial, como André Rebouças, Joaquim Nabuco, Rui Barbosa, Tavares Bastos, José do 
Patrocínio e Luiz Gama, utilizavam os jornais para expressarem suas concepções e suas ações políticas. Assim, ao analisar a atuação de Cardoso Vieira, o considero um homem típico da elite do século XIX, cujas funções e inserções sociais eram variadas. No entanto, como já dito, Cardoso Vieira carregava uma dessemelhança em relação a muitos dos seus companheiros de partido político, 0 Liberal. 0 que o diferenciava era 0 fato de ser um homem negro livre, letrado, possuidor de propriedades e que se envolveu em alguns dos debates mais importantes do final do século XIX, como a questão do Abolicionismo. Durante muito tempo, a historiografia brasileira obscureceu as trajetórias dos indivíduos negros livres. Em geral, os estudos históricos sobre a população negra destacavam sobremaneira a sua atuação como trabalhadores escravizados e pouco evidenciavam a história daqueles que não estavam vinculados diretamente à escravidão. $O$ desvelamento da origem racial de Cardoso Vieira contribuiu para a desconstrução da ideia de que pessoas negras do Oitocentos eram, em geral, escravizadas. Ele era um homem livre, sem vínculos biológicos diretos com o cativeiro, ${ }^{9}$ mas que vivia numa sociedade escravista, marcada por relações hierárquicas e autoritárias, na qual ele não foi uma exceção. Os relatos sobre seu comportamento social nos mostram que ele era resultado da sociedade oitocentista e se aproximava de seus contemporâneos não negros.

Acerca do seu comportamento, é ilustrativa a descrição física feita sobre ele, quando exercia 0 cargo de professor de Retórica no Lyceu Provincial da Paraíba, nos anos inicias de 1870. Para ministrar suas aulas, costumava ir acompanhado de um "pagem, à moda do tempo, e dava aulas de botas e esporas" (CARVALHO, 1948, p. 93). Não é demais sugerir que esse acompanhante/pajem de Cardoso Vieira poderia ser um escravizado, visto que seu pai era um proprietário de cativos. Ademais, sua indumentária reforçava sua masculinidade e autoridade e indica também aspectos de personalidade, descrita como marcante, afirmava Carvalho (1948, p. 95), Cardoso Vieira era "um mestiço, alto, forte, de rosto grande e traços impressionantes".

Na década de 1940, outro intelectual do IHGP e da APL, Manoel Tavares Cavalcanti (18801950), ${ }^{10}$ como representante da Academia Paraibana, proferiu conferência na Federação das

9 A afirmação a respeito da condição jurídica de Cardoso Vieira é feita com base nas evidências empíricas disponíveis. Contudo, outros estudos podem alargar as informações a respeito da condição jurídica de seu pai ou de sua mãe.

10 Manuel Tavares Cavalcanti (1880-1950) é mais um exemplo de homens de elite do Oitocentos, pois era um letrado e exerceu cargos políticos. Foi sócio-fundador do IHGP, em 1905; tornou-se patrono da Cadeira 36 da Academia Paraibana de Letras; na política exerceu variados cargos, de Deputado Estadual (1907), depois exerceu o mandato de deputado federal por cerca de 20 anos e atuou como senador da Paraíba (1930). Além disso, foi professor do Liceu Paraibano e de Direito Romano na Universidade Católica do Distrito Federal. Informações disponíveis no portal do IHGP: 
Academias de Letras. Na ocasião, sistematizou a vida da intelectualidade paraibana, cujo texto recebeu o título de Retrospectiva da vida intelectual da Paraíba. Acerca do paraibano negro, trouxe-nos informações sobre sua atuação no Parlamento brasileiro, como deputado geral, entre os anos de 1879 e 1880, na $17^{\text {a }}$ Legislatura. Cavalcanti $(1995$, p. 50) destacou, primeiro, que Cardoso Vieira era "um das mais fortes mentalidades que a Paraíba tinha produzido. Muito se distinguiu no curso [de Direito, em Recife], figurando entre os maiores expoentes da faculdade, era poeta e orador". A respeito de sua atuação, após a conclusão do Curso de Direito, referiu que, na Paraíba, "conquistou com brilhante concurso uma cadeira de professor no Liceu Paraibano", "figurou, com grande relevo, na imprensa e na Tribuna política e judiciária e travou sérias polêmicas com Padre Lindolfo". No cenário nacional, em 1879, foi eleito deputado em Assembleia Geral. Porém, logo se opôs ao [Presidente do Conselho dos Ministros] presidido pelo Visconde de Sinimbu (1810-1906), chefe de seu partido [Liberal], e se tornou um dos mais aplaudidos oradores da dissidência liberal. $O$ autor conclui nos informando que coube a Joaquim Nabuco realizar o seu necrológio, que salientou seu "ardor abolicionista".

Como podemos observar, os homens da elite paraibana mantinham uma visão positiva da vivência política e intelectual de Cardoso Vieira e procuravam consagrá-lo com um homem de grandes "feitos" para a Paraíba. No artigo de Manoel T. Cavalcanti, novamente, as informações indicam que a figura pública do personagem em análise sempre chamava a atenção dos intelectuais paraibanos, que destacavam sua inteligência - porque muito se distinguiu no Curso [de Direito], no concurso do Lyceu Provincial, e "figurou com grande relevo na imprensa e na Tribuna" - e seu bom desempenho ao desenvolver várias atividades (de poeta, professor, orador, jornalista etc.) e polêmicas políticas (quando estudante, fez críticas aos professores, e, quando deputado geral, realizou questionou o Ministério presidido pelo liberal Visconde de Sinimbu e foi considerado ardoroso abolicionista).

Apesar dessas manifestações do prestígio de Cardoso Vieira, ao longo das décadas do século $X X$, verifiquei que houve um prazo longo para a inauguração da sua Cadeira 10, na APL. Depois de trinta e um anos da criação da Academia, em 1988, o historiador José Octávio de Arruda Mello (nascido em 1940 e que se tornou membro da APL e do IHGP no ano de 1972) foi eleito o primeiro ocupante da sua cadeira. Em 1960, essa mesma cadeira havia sido destinada ao político Otacílio Nóbrega de Queiroz (1913-1998) e integrante do IHGP (desde 1965), contudo ele nunca tomou posse. Esse é um dos "mistérios" não solucionados da APL, segundo Guimarães (2001), que levanta a hipótese de ter havido um "estremecimento entre ele [Otacílio] e José Américo de Almeida, com troca de artigos ferinos pelos jornais" (GUIMARÃES, 2001, p. 56). 
Sobre os escritos que procuraram fixar uma memória sobre Cardoso Vieira, destaco um dos estudos mais expressivos sobre a trajetória do intelectual negro. Trata-se da sua biografia, elaborada por Martins, em 1979, nas proximidades do centenário de sua morte. O autor aborda detalhamento de sua vida política e intelectual, com indicação de fontes sobre os vários episódios que envolveram o jornalista paraibano. Talvez Martins, um homem vinculado à APL (sua entrada ocorreu em 1971) e ao IHGP (associado a partir de 1975), informado das dificuldades de se terem informações de alguns dos patronos da APL ${ }^{11}$, tenha se empenhado em coletar e sistematizar fontes sobre alguns intelectuais do século XIX, que resultaram nas biografias de Eliseu Elias Cézar (1975) e de Cardoso Vieira (1979). Outra hipótese é de que Martins poderia estar dando continuidade à tarefa iniciada por Castro na década de 1950, com a publicação do livro Vultos da Paraíba, em que esse autor relatou as dificuldades de recuperar a memória dos patronos da APL, uma vez que nem todos "deixaram em documentação escrita a marca do seu valor" (CASTRO, 1955, p. 04) ou para complementar o artigo de Carvalho publicado em 1948.

Como ressonância da publicação do livro de Martins, no mesmo ano, Geraldo Irineu Joffily uma escreveu reportagem intitulada Cardoso Vieira, um paraibano de idéias avançadas, publicada no Jornal O Momento (junho de 1979). ${ }^{12}$ Nesse artigo, Joffily fez uma breve resenha do livro aludido, em que emitiu opiniões sobre Cardoso Vieira e, a partir de uma leitura de sua fotografia disponível nos escritos de Martins, classificou-o como "mulato escuro, cabelo bem enrolado e aparado" [...] e, sobre as vestimentas, registrou que estava "bem trajado e engravatado, pois era um filho legítimo de um abastado dono de terras, senhor de muitos escravos." A respeito de sua vida, destacou sua inserção como jornalista e político na Corte imperial e qualificou-o como uma "das maiores figuras do Parlamento no Segundo Reinado, tendo em vista a independência de suas atitudes". Como podemos perceber, o tempo passava, quase cem anos após sua morte, e ele mantinha-se com prestígio entre os intelectuais da Paraíba.

Além da atualização da memória de Cardoso Vieira feita por homens de letras do IHGP e/ou APL, recentemente, ele passou a ser observado por estudiosos acadêmicos. Assim, em meu trabalho 
de Doutorado, defendido em 2007 e publicado em 2009, estudei fragmentos de sua história de vida, visando evidenciar as diferentes categorias jurídicas das pessoas negras no Oitocentos. Cardoso Vieira foi importante para se exemplificar a situação social de uma pessoa negra livre. Por isso procurei destacar sua origem social. Sobre a qual evidenciei os seus pais eram: proprietários de terra e escravizados na freguesia do Conde; politicamente, o seu pai era partidário do Partido Conservador, já Cardoso Vieira esteve nas fileiras do Partido Liberal; profissionalmente, atuou como professor e jornalista (ROCHA, 2009). Já Ferronato (2012), em tese sobre a História da Educação na Paraíba oitocentista, enfatizou sua atuação como professor do Lyceu Provincial e nos informa que, no ano de 1872, concorreu a um concurso para a cadeira de Retórica naquela instituição de ensino secundário, cujos examinadores foram os professores Thomas de Aquino Mindelo e o Padre Leonardo Antunes Meira Henriques. Depois de ter sido aprovado, sua nomeação foi publicada em 01 de junho de 1872.0 mencionado concurso era normatizado pelo Regulamento de 11 de março de 1852 (FERRONATO, 2012, p. 187). ${ }^{13}$ Outro trabalho versou sobre Cardoso Vieira (BISERRA, Ingrid K. C. et al., 2012), no qual os autores apresentam preliminarmente análise sobre a sua atuação parlamentar, nos anos de 1878 e 1879, tendo como base dezessete discursos proferidos na Assembleia Geral.

Com a análise de algumas facetas de Cardoso Vieira, podemos observar como são construídos a memória individual, ao longo do tempo, e os sentidos dados a ela nos diferentes contextos. Para os homens de letras da Paraíba, a trajetória de vida de Cardoso Vieira foi utilizada com o objetivo de valorizá-lo como letrado do Século XIX, razão por que se exaltou a intelectualidade de um território, o da Paraíba, uma vez que ele foi considerado como um dos vultos da Paraíba com valor. Para outros, como estudiosos acadêmicos, revisita-se essa memória para propor outras visões históricas sobre a população negra e desconstruir imagens cristalizadas pela historiografia de negros associados unicamente à escravidão. Além disso, ao se recuperar sua trajetória de vida, com o intuito de evidenciar sua experiência histórica, com base na problematização, na crítica e na reflexão da memória, identifica-se um campo permeado de tensões e de revelações, nem sempre pretendidas, como, por exemplo, sua condição de proprietário de escravizados.

Todavia, um dos papéis da história é compreender a presença humana no tempo, as contradições, as continuidades e as permanências históricas, os silêncios dos não ditos (FÉLIX, 1998, 
p. 42-45). No presente artigo, no qual se refere a um homem negro, procurei discutir a memória dos que não foram reconhecidos ao longo da produção de conhecimentos sobre as suas vivências do passado, mostrando sua experiência na sociedade escravista do Oitocentos.

Para finalizar, vale assinalar que com o estudo do "enquadramento da memória" de Cardoso Vieira, identificamos a sua permanência na memória local como um "vulto da história da Paraíba", e também recuperamos a presença negra na sociedade paraibana, especialmente no interior das elites imperiais, mostrando a complexidade da sociedade escravista, com base na experiência do personagem em análise que, se de um lado, conseguiu alterar alguns posicionamentos políticos mudou do partido Conservador para o Liberal, integrou o grupo dos abolicionistas no Parlamento -, de outro, fez parte de uma família proprietária de escravizados e sempre conviveu com a posse de cativos. Assim, apesar de compor o grupo dos liberais reformistas, ${ }^{14}$ organizados a partir da queda do gabinete liberal, em 1868, ele continuava a ser um proprietário de escravizados. Talvez, Cardoso Vieira fosse um homem do seu tempo, que considerava natural a escravização de pessoas, ou também, mesmo colocando-se como abolicionista, não tenha conseguido se desprender completamente dos valores da sociedade escravista que atingiam a população em geral, independentemente da origem racial e da condição econômica, nos mostrando a complexidade dos sujeitos sociais que viveram nos anos finais da sociedade brasileira oitocentista.

\section{REFERÊNCIAS}

ALMEIDA, José Américo de. A Paraíba e seus problemas. João Pessoa: FCJA; Brasília: Senado Federal, 1994[1923].

ANDREWS, George R. América Afro-latina (1800-2000). Tradução Magda Lopes. São Carlos: EdUscar, 2007.

BISERRA, Ingrid K. C. et al. História intelectual, imprensa e atuação parlamentar: uma análise preliminar do pensamento de Manoel Pedro Cardoso Vieira. In: FERRONATO, Cristiano; NUNES, Maria Lúcia da S.; ARAÚJO, Rose Mary de S. (Orgs.). Anais Eletrônicos do IX Seminário Nacional de Estudos e Pesquisas "História, Sociedade e Educação no Brasil”. João Pessoa, 2012. 
BORGES, Vavy P. Fontes biográficas: grandezas e misérias da biografia. In: PINSKY, Carla B. Fontes históricas. São Paulo: Contexto, 2005, p. 203-233.

BOSI, Alfredo. A escravidão entre dois liberalismos. In: Dialética da colonização. São Paulo: Companhia das Letras, 1992, p. 194-245.

CARVALHO, Álvaro de. Notas sobre Cardoso Vieira. Revista da Academia Paraibana de Letras. João Pessoa, n. 4, ano II, 1948, p. 89-45.

CARVALHO, José Murilo de. A construção da Ordem: a elite política imperial. 2 ed. Rio de Janeiro: Ed. UFRJ; Relumé-Dumará, 1996.

CASTRO, Oscar. Vultos da Paraíba (Patronos da Academia). Rio de Janeiro: Departamento de Imprensa Nacional, 1955.

CAVALCANTI, Manoel Tavares. Retrospectiva da vida intelectual da Paraíba. Revista do Instituto Histórico Geográfico Paraibano. João Pessoa, n. 9, out. 1995, p. 09-51.

CONRAD, Robert. Os últimos anos da escravidão no Brasil. 2. Ed. Tradução Fernando de Castro Ferro. Rio de Janeiro: Civilização Brasileira, 1978.

FÉLIX, Loiva O. História e Memória: a problemática da pesquisa. Passo Fundo: EDUPF, 1998.

FERRONATO, Cristiano de J. Das aulas avulsas ao Lyceu Provincial: as primeiras configurações da instrução secundária na Província da Parahyba do Norte (1836-1884). João Pessoa, Tese (Doutorado), Centro de Educação, Programa de Pós-graduação em Educação (PPGE/UFPB), 2012.

GUIMARÃES, Luiz Hugo. História da Academia Paraibana de Letras. João Pessoa: A União, 2001.

MARIZ, Celso. Apanhados históricos da Paraíba. 2. Ed. João Pessoa: Universitária/UFPB, 1980.

MARTINS, Eduardo. Memória histórica da Academia Paraibana de Letras (1941-1978). Revista da Academia Paraibana de Letras. João Pessoa, n. 9, set. 1984, p. 215-230.

Elyseu Elias Cézar: notícia biográfica. João Pessoa: mimeo, 1975. (Discurso de posse no Instituto Histórico e Geográfico da Paraíba, em 22 de novembro de 1975).

Cardoso Vieira e o Bossuet da Jacoca. Nota para um perfil biográfico. João Pessoa: Secretaria da Educação e Cultura, 1979.

MATTOS, Hebe M. Escravidão e cidadania no Brasil monárquico. Rio de Janeiro: Jorge Zahar, 2000.

MELLO, Evaldo C. de. 0 Norte agrário e o Império, 1871-1889. 2. Ed. Rio de Janeiro: Topbooks, 1999.

MELLO, José Octávio de Arruda. A escravidão na Paraíba. Historiografia e história: preconceitos e racismo numa produção cultural. João Pessoa: A União, 1988. 
NASCIMENTO, Abdias. A luta afro-brasileira no Senado. Carta: falas, reflexões, memórias: informe de distribuição restrita do senador Darcy Ribeiro. Brasília: Gabinete do senador Darcy Ribeiro, n. 1, 1991, p. 33-52.

NORA, Pierre. Entre memória e história: a problemática dos lugares. Projeto História, n. 10, 1993, p. 7-28.

POLLAK, Michael. Memória, esquecimento, silêncio. Estudos Históricos, v. 2, n. 3, 1989, 3-15.

PRADO, Maria Emília. Ordem liberal, escravidão e patriarcalismo: as ambiguidades do Império do Brasil. In: PEIXOTO, Antonio Carlos et al (Orgs.). 0 liberalismo no Brasil imperial: origens, conceitos e prática. Rio de Janeiro: Revan; UERJ, 2001, p. 163-189.

ROCHA, Solange P. Gente negra na Paraíba oitocentista: população, família e parentesco espiritual. São Paulo: Unesp, 2009.

RODRIGUEZ, Walfredo. Roteiro sentimental de uma cidade. São Paulo: Brasiliense, 1962.

SCHMIDT, Benito B. "Grades invisíveis para rebentar": memórias de um militantes de esquerda brasileiro sobre as prisões argentinas (1975-1979). In: AVELAR, Alexandre de Sá; SCHMIDT (Orgs). Grafia da vida: reflexões e experiências com a escrita biográfica. São Paulo: Letra e Voz, 2012, p. 227-239. 